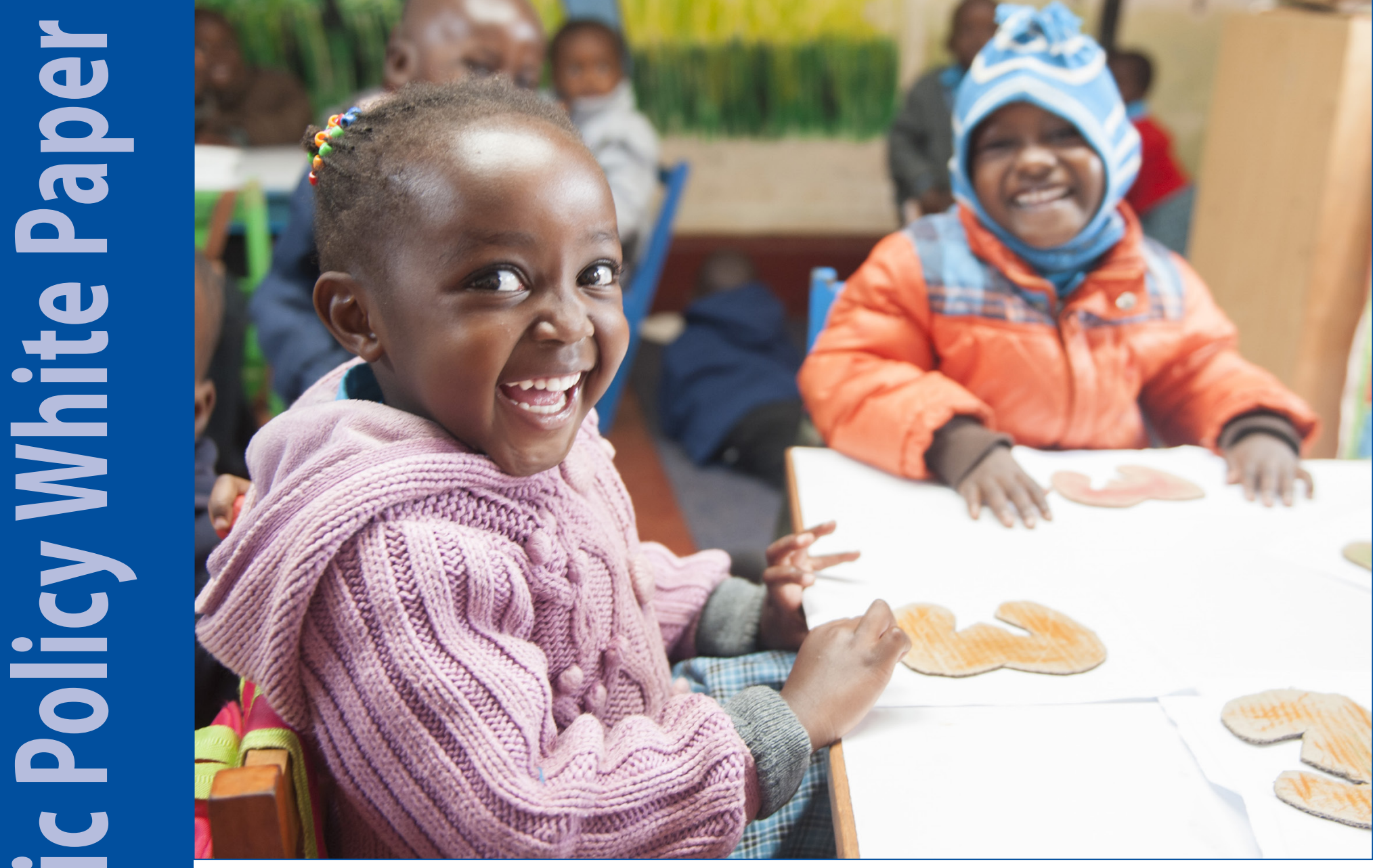

"The Kidogo Way" utilizes a play-based and localized curriculum to create a safe and stimulating environment in each childcare center. Photo courtesy of Kidogo.

\title{
Kidogo: Addressing the Childcare Needs of Low-Income Families in East Africa
}

By: Jill Howard, Fiona Wilson, and E. Hachemi Aliouche

September 28, 2020 


\section{Introduction}

Ninety percent of brain development takes place before the age of five, and while universally agreed to be pivotal in defining the trajectory of a child's life, access to high-quality Early Childhood Care and Education (ECCE) is often inaccessible for the world's most vulnerable populations. The United Nations estimates that over 200 million children globally fail to reach their full potential as ECCE continues to be neglected in developing countries (Ritcher et al., 2016). For the 2.5 million children living in East Africa's informal settlements, there is an urgent need for an affordable, highquality childcare option that is able to scale quickly to serve the masses (Black et al., 2016).

To unlock the potential of this region's millions of children, Kidogo, an innovative East African social enterprise, is harnessing the power of social sector franchising. Kidogo partners with women running informal daycares in Kenya's urban slums to better the condition and profitability of their micro-businesses. By working with local women entrepreneurs, "Mamapreneurs," and drastically improving the quality of Kenyas early childhood care and education, Kidogo is altering the course of low-income families to help stop the generational cycle of poverty.

Social sector franchising applies proven concepts and systems of traditional franchising to mission-driven businesses in fields such as health care, clean energy, education, and nutritional access to broaden the reach of life-altering social services. A successful social sector franchisor leads a network of easily replicated, locally owned businesses under the same model, branding, and mission.

This case study explores how Kidogo was first formed as well as the current business and franchising model by which it operates. By discussing Kidogo's combination of best-practice early childhood Centres of Excellence with a social franchising method that supports the quality improvement and growth of local childcare micro-businesses, this case study provides insight into Kidogo's expansion and success and looks forward to the future of the organization.

As of August 2020, Kidogo operated three corporateowned Centres of Excellence and supported 139 microbusinesses owned by Mamapreneurs in twelve informal settlements across Kenya. Kidogo has directly impacted 2,886 children leading to an estimated indirect impact of nearly 12,000 low-income Kenyans.

\section{About This Case Study}

This case was examined as part of the Social Sector Franchise Initiative, a collaborative undertaking at the University of New Hampshire (UNH) between the Rosenberg International Franchise Center (a program of the Peter T. Paul College of Business \& Economics) and the Center for Social Innovation and Enterprise (now the Changemaker Collaborative), a joint venture between the Sustainability Institute, the Peter T. Paul College of Business and Economics, and the Carsey School of Public Policy. The International Franchise Association (IFA) is a key external partner.

A key part of the initiative, the Social Sector Franchise Accelerator (SSFA) was a nine-month program which ran from 2016 to 2019, where nascent social sector franchises were selected from a pool of applicants. Accelerator participants were provided with coordinated intensive mentorship by commercial franchise experts from the IFA, online learning, and an eco-system of support. The process included an active learning and research component conducted and documented by UNH faculty and students, culminating in a series of published case studies.

\section{Context}

Intergenerational cycles of poverty persist by way of the limited options for healthy and developmentally supportive childcare options in East Africa. For a working mother in the region's informal settlements, pulling older siblings (usually girls) out of school, or paying a fee to drop their children off at an unlicensed and overcrowded daycare center for 12 to 14 hours of the day, are the only childcare choices. With 60 percent of Nairobi's population living in the slums, rapid urbanization is resulting in small, dark, unsanitary, and low-quality childcare centers with close to 25 children being cared for by one woman in a 10 foot by 10 foot space. As a result, children in Nairobi's informal settlements are the unhealthiest nationwide. Over 50 percent suffer from stunted 
development due to chronic malnutrition and most are ill-prepared for school and life due to a lack of developmental attention (Mwase et al., 2016; Ezeh et al., 2016; Lu et al., 2016).

Further, the women running these childcare centers are living in deep poverty and thus are highly motivated to increase their profits beyond the average \$50-\$80 USD per month. The typical childcare operator is a 28 -year old woman living in Nairobi's urban settlements without a high school diploma. She makes a living through odd jobs but is unable to do door-to-door work after having her first child. Impacted by a multitude of other issues magnified by poverty, such as HIV/AIDS and domestic abuse, she decides to open her own daycare, buying an $\$ 8$ USD mattress for her small corrugated metal shack. Not knowing what to do with 8 to 10 children for over 12 hours a day, 6 days a week, she often leaves them laying on the mattress. In some cases, she gives them alcohol or Peritol, a sleeping drug, to keep them hushed through the day. In spite of her hard work, she has no way of tracking how much money she is earning but still finds it is not enough.

While the childcare operators are harnessing their resources to the best of their abilities, the children they care for often suffer. In environments such as these, illnesses and diseases spread quickly: the HIV/AIDS prevalence rate in Kenya's informal settlements are over double the national average. In addition, food insecurity affects about 85 percent of households in the informal settlements, resulting in malnutrition as a leading indirect cause of childhood mortality and compromising healthy brain development and cognitive functioning for those who are able to grow to adulthood (Olack et al., 2011).

Mothers of these children face significant challenges as well. Mothers are often absent from work, caring for chronically sick children who easily catch infections at informal daycares, and if they are present, are less productive because they are constantly worried about the wellbeing of their children. With mothers who are not able to thrive economically and children who are not reaching their full developmental potential, families are further locked into generational cycles of poverty (Ezeh et al., 2016).

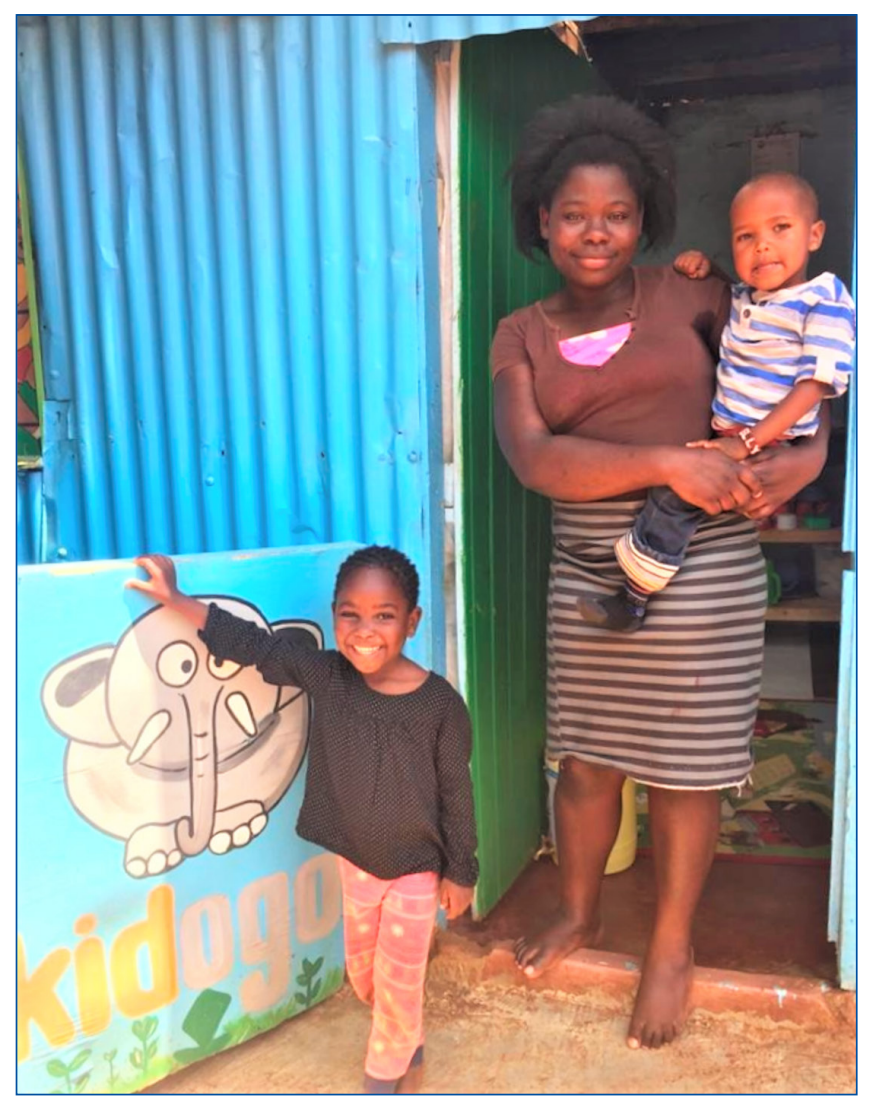

After reaching a minimum level of quality standards, Mamapreneurs are eligible to receive Kidogo branded signage and funding for small restructuring and innovations. Photo courtesy of Kidogo.

\section{The Beginning of Kidogo}

Prior to Kidogo's launch in 2014, Sabrina Natasha Habib, Co-Founder and Chief Exploration Officer, was working at the Aga Khan Development Network in East Africa managing an Integrated Primary Health Care grant. It was during this time, in December of 2011, that she was first introduced to the best childcare option for Kenyan mothers living in informal settlements: a dark 10 foot by 10 foot corrugated metal shack, smelling of urine and feces and absent of the usual joyful noise of a group of children. As a first-generation Canadian whose parents had immigrated from East Africa in the 1970s, Sabrina felt innately connected to the issue, thinking: "this could have been me." Frustrated with traditional development approaches that were donor 
dependent and/or standalone, Sabrina and her now husband Afzal Habib, a Toronto-based management consultant, became dedicated to finding a childcare solution that would be sustainable, scalable, highquality, and most importantly, affordable for the mothers of East Africa's low-income communities.

\section{The Kidogo Method}

Through Kidogo, Sabrina and Afzal are not only providing a rich source of affordable, high-quality childcare, they are also providing the training, mentorship, and tools that childcare operators, or "Mamapreneurs" as they have coined them, need to grow their businesses. Kidogo is able to find potential franchisee Mamapreneurs by mapping existing daycares in an informal settlement and working through the community network to run workshops for those who might be interested. Once a Mamapreneur opts into the program, she is taken through a six-month accelerator-type program focused on the basics of early childhood development and entrepreneurship (called "The Kidogo Way"). The program consists of a monthly workshop followed by bi-weekly coaching visits from Kidogo staff. At the same time, Mamapreneurs join a "Community of Practice" where they are able to meet other Mamapreneurs in their area every month to share their challenges and celebrate successes. This peer-to-peer support fosters accountability and a sense of belonging, ultimately leading to increased retention rates. To participate in this accelerator, Mamapreneurs pay a nominal fee of $\$ 5 /$ month. Because daycare operators are repeatedly told they were "not good enough to become real teachers," Kidogo primes its work by promoting confidence within the Mamapreneurs by helping them explore their identities and the value they bring to their community.

Kidogo developed a set of quality standards based on the six elements of the Kidogo Way: (1) safe, stimulating environments, (2) responsive caregivers, (3) play-based activities, (4) health, nutrition, water, and sanitation, (5) parent and community engagement, and (6) business and administration. Kidogo works with Mamapreneurs to improve their operations on each area until their centers score a "green" on a red, yellow, green scale. At that point, the center is eligible to become a Kidogo franchisee. They receive Kidogo branded signage and a small renovation (generally costing \$250 USD), making it a more comfortable space for the Mamapreneur and the

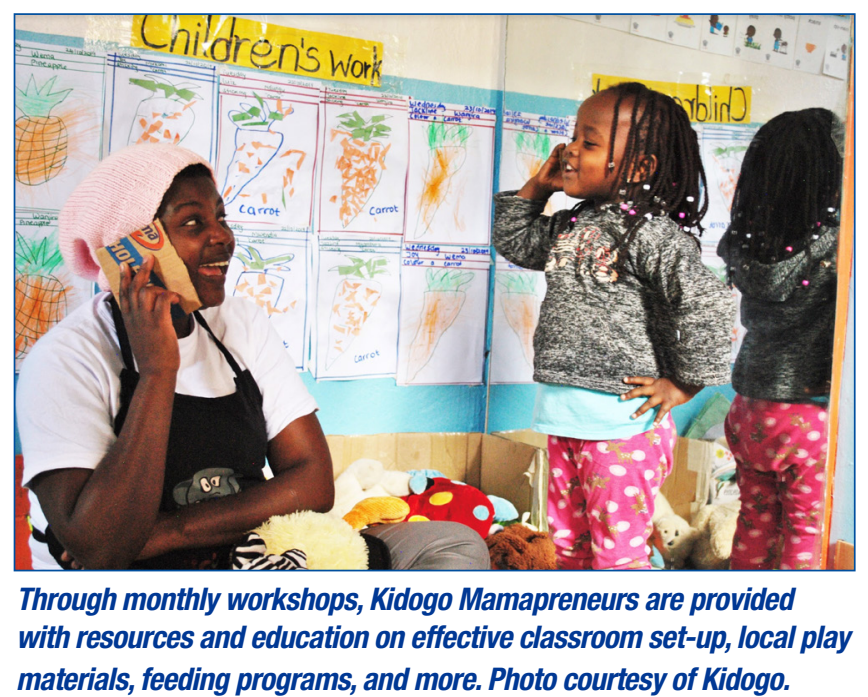

children she cares for, and signaling to the community that this is a quality center. She also is given access to a Starter Kit, with a manual on how to operate and manage a childcare center effectively, and the Mamapreneur App, a phone-based application to efficiently and easily track the attendance and payments of her customers. For long-time franchisees, Kidogo provides opportunities for Mamapreneurs to grow their operations by either adding additional classes or becoming a multi-unit franchisee (that is, owning multiple centers in the same geography).

\section{The Kidogo Business Model and Franchise Approach}

Kidogo's method is carried out through a Hub and Spoke model that fosters its success as a nimble, learning-based organization. Three Centres of Excellence are owned and operated by Kidogo HQ and act as best-practice models (hubs) for childcare and early learning as well as training facilities for Mamapreneurs. While offering exceptional, high-quality childcare, the Kidogo Centres of Excellence also serve as research and development labs where the company can test out small innovations and, if successful, roll them out to the network of Mamapreneurs. The 139 spokes to the model are the childcare micro-businesses owned by a supportive network of Mamapreneurs provided with ongoing training, mentorship, and quality-improvement tools. Franchising Officers, trained and deployed by Kidogo $\mathrm{HQ}$, act as the glue between the Centres of Excellence (hub) and Mamapreneurs (spokes), travelling to each Mamapreneur to provide on-site assistance and ensure quality standards are being met. 
Kidogo's Hub and Spoke model and the context in which it is operating create a prime opportunity to use social franchising as a pathway to ultimate scale and success. An existing market of about 3,000 informal, makeshift daycares in Nairobi's informal settlements serving 8 to 30 children each are providing a necessary service to working mothers and an income to the women operating them. Though currently unable to meet Kidogo's quality standards, these existing daycares represent a ripe opportunity for Kidogo to expand its reach into new communities.

In the thousands of unsafe daycares where low quality regularly results in the loss of life, the need for standard quality compliance mechanisms, a core component of the franchising model, taught by Kidogo HQ and enforced by Franchising Officers, could not be more urgent. Improving not only the quality but also the profitability of these childcare centers while maintaining their local ownership status is less costly for Kidogo as a franchisor. Once centers become franchisees, it costs Kidogo less than $\$ 10$ per month to provide the necessary quality assurance and refresher trainings to maintain quality services. More importantly, it builds the entrepreneurial spirit and job opportunities for thousands of people living in poverty in Kenya's low-income communities. By franchising, Kidogo is hoping to have an "all boats rise" effect in East Africa. Kidogo aims to convert 15 percent of the childcare centers in any given community to Kidogo franchisees and consequently, place competitive pressure on surrounding centers to improve their quality while maintaining a similar price point.

Currently, 24 percent of childcare centers in the 12 communities Kidogo works in are part of the network and early research indicates that Kidogo parents have shifted how they make childcare decisions. Instead of relying on proximity, price, and convenience, Kidogo parents look for positive caregiver to child interaction, engaging activities and nutrition as their top three factors in choosing a childcare center. Kidogo is demonstrating how supplying quality childcare services can shift consumer demand toward factors that are important for child development, and that will ultimately elevate the provision of community-based childcare.

\section{An Innovative Approach}

While Kidogo faces some competition in the Kenyan childcare market, the organization credits its success to the affordability of its services. While other providers have moved upmarket to increase fees and effectively price out the families who need their services the most, Kidogo childcare centers cost less than $\$ 1$ per day. This price is roughly 15 to 20 percent of household income.

Another unique cornerstone of the organization's success is its holistic approach to early childhood care and education. "The Kidogo Way" methodically outlines each childcare center's building blocks for success by promising a safe and stimulating environment; trained and loving caregivers; play-based and localized curriculum; comprehensive health, nutrition, water, and sanitation programs; and a parental outreach strategy which ensures the continuum of learning and development into the home. The Kidogo Way aligns to the World Health Organization, World Bank, and UNICEF's global Nurturing Care Framework.

The sustainability of the organization can be attributed to the business structure created by Sabrina and Afzal. Prior to Kidogo, inadequate solutions to the issue were short-term, philanthropy dependent "projects" without a defined system for maintaining partnerships, revenue, or quality over time. Kidogo's Hub and Spoke model has the ability to operate and expand in a cost-effective way and is further strengthened by the transferable systems created through franchising.

\section{Proving the Model: Kidogo Impact}

The comprehensive and inventive approach Kidogo has taken to implementing its Hub and Spoke franchising model has proven to produce impactful results. Many women enter the program ranking as "inadequate" on a global scale of quality called the Infant-Toddler Environmental Scale and transition to "minimal" level of quality in a mere 6-month period. Children are healthier, reporting a 29 percent reduction rate in stunting levels, and transition to primary school, quickly ranking in the top 5 percent of their classes. A recent study found Kidogo kids who had graduated to primary school outperformed a control group in all areas of development, particularly in emotional regulation and executive function, which is critical for working memory and cognitive flexibility. 


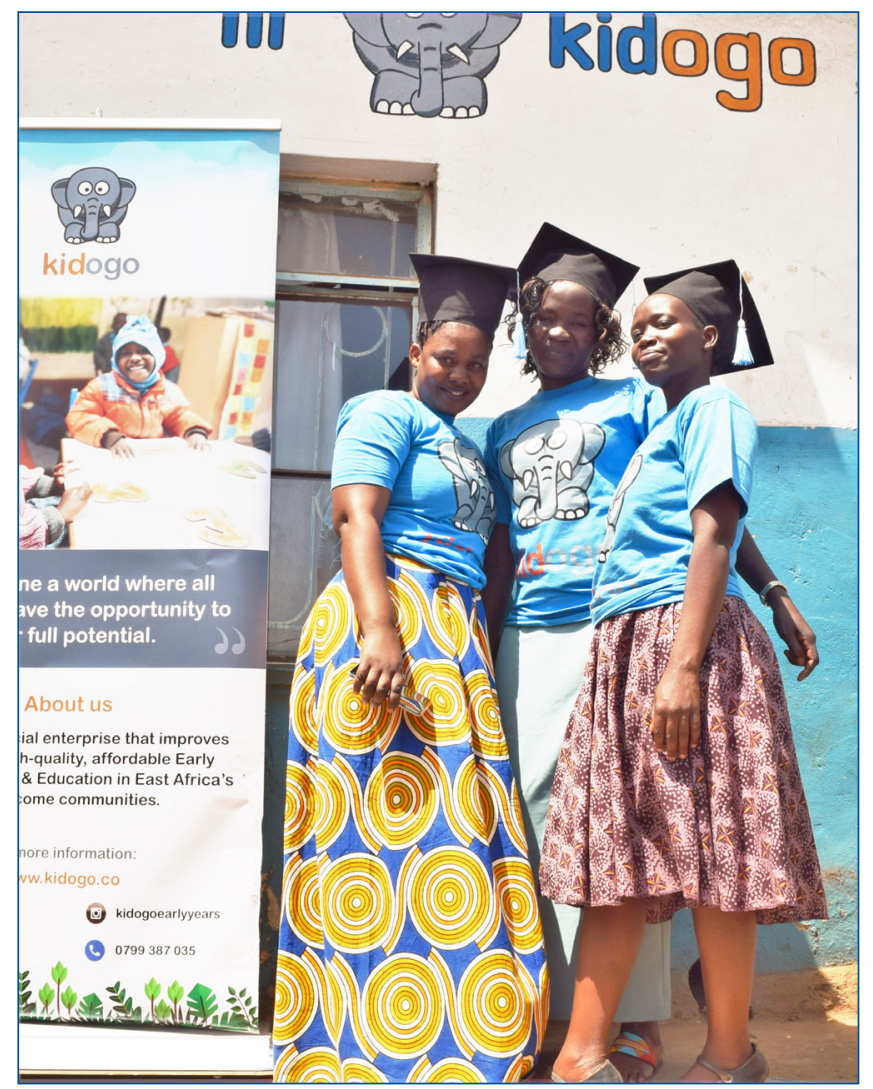

Upon successful completion of the Kidogo program, Mamapreneurs are recognized at a "Mamapreneur Gala." Photo courtesy of Kidogo.

For the Mamapreneurs who may not last through the entire training phase or ultimately become a franchise, Kidogo's efforts are still beneficial and assist in even small improvements to the childcare centers. Increased exposure to word count, more structured activities for holistic development, and stronger nutrition programs are just some of the ways Kidogo is positively impacting Nairobi's childcare ecosystem beyond their own hub and spokes. In other efforts to improve the childcare ecosystem and advocate for more minimum childcare standards for Nairobi County, Kidogo is a Founding Member of the Early Childhood Network for Kenya, alongside UNICEF, World Vision, and the Aga Khan University. The Network was responsible for helping Nairobi County pass the Childcare Facilities Act in 2017. As a testament to the organization's impact, Kidogo holds a net promoter score of 58-extremely good based on industry standards. As part of the customer satisfaction surveys Kidogo conducts at the end of each school term to gather this data, they also collect testimonials from the parents of the 2,886 children Kidogo affects each day. Parents of the children at Kidogo centers boast:
"I can do work easier knowing that my son is in a safe place"; "She used to be quiet but now she speaks a lot and knows how to express herself"; "I have peace of mind because my child is well taken care of."

\section{Future of the Franchise Model}

As the Hub and Spoke franchise model continues to expand Kidogo's impact in structured, effective ways, Kidogo has recently concluded testing the benefits of a conversion versus path to ownership model for their spoke centers. A converted center is created using the model Kidogo has traditionally employed: recruiting Mamapreneurs who already have childcare centers but are looking for the resources and support to improve their quality and profitability. Pre-existing childcare centers that are converted to meet Kidogo's quality standards have the benefit of existing trust in the Mamapreneurs who have already been looking after many children. Further, working from existing spaces is a more cost-effective model for Kidogo's expansion as it requires fewer resources and supplies to start up.

Path to ownership models, on the other hand, hire women who do not already have a childcare center but have positive reputations in the communities. These newly formed centers almost always demonstrate higher quality and are free from the barrier of "unlearning" but, conversely, are more costly and do not benefit from the pre-existing trust of mothers in the community. Over a period of 12 months, the center's ownership transfers from Kidogo to the Mamapreneur.

After testing the scalability and success of each model (with half of their franchises as conversions and half as path to ownership centers), Kidogo believes the conversion model will provide the best path to scalability in communities densely populated with daycares, and will reserve the path-to-ownership model for communities with fewer daycares.

\section{Looking Ahead for a Bold Future}

As Sabrina Habib looks toward Kidogo's future, her long-term goal is for the organization to become a leading player in childcare services in East Africa. Moving into new communities, let alone entirely new countries, can be difficult, though. Kidogo is eager to perfect a method for building trust in the communities they work in by partnering with people and organizations that already have trusted 
relationships in the area. Through the relationships they build with community chiefs and healthcare centers, Kidogo will ensure the parents in the community feel comfortable leaving their children with Kidogo Mamapreneurs.

With growth on the horizon, Kidogo is continuing to be a pioneer of innovative systems and structures for childcare. Childcare is hardly a profitable field-especially in the circumstances under which Kidogo is working. Almost nowhere in the world is childcare provided in a low-income area without a subsidy. Because quality is costly and income is scarce in the informal developments of Nairobi, Kidogo is exploring offering performance bonuses to their Mamapreneurs in order to subsidize the cost of quality (notably, reducing the caregiver to child ratio), ultimately hoping to prove the benefits of this payment to the Kenyan Government and transfer the role of subsidizer over to them.

On another front, Kidogo is currently working with the International Finance Corporation and other private sector players globally to test a model in which the childcare centers are run through and subsidized by the parent's employers. Access to childcare has been shown to boost productivity and reduce stress and absenteeism in female workers, and Kidogo is keen to bring the benefits of employer-supported childcare to East Africa.

With expansion into new countries and budding corporate and civil society partnerships, as well as the development of a newly introduced app for Mamapreneurs to track their finances and systems on the horizon, Kidogo is committed to staying ahead of the childcare market while keeping quality of the utmost importance. Moreover, Kidogo continues to advocate for conducive policies such as childcare licensing and minimum standards in order to professionalize the field.

As Kidogo grows its franchises, its impact on the healthy development of children living in Kenya as well as the personal and financial empowerment of the Mamapreneurs caring for these children will begin to multiply quickly. By thoughtfully harnessing the existing market and local ownership to franchise a model that addresses the lack of quality in early childcare and education, Kidogo is primed to make a lasting impact on the social and economic development of East Africa.

\section{Methodology}

This case study was developed over a period of three months in the Summer of 2019 following the 2018-2019 Accelerator Program. It includes data from working sessions with company leaders, regular mentor/mentee phone calls, and company research gathered throughout the nine-month accelerator. In-depth interviews with Kidogo's leaders were supplemented with companyprovided documents and secondary data.

\section{References}

Black, Maureen M., Walker, Susan P., Fernald, Lia C. H., Anderson, Christopher T., DiGirolamo, Ann M., Lu, Chunling, et al. "Early childhood development coming of age: science through the life course." October 4, 2016. https://www.thelancet.com/journals/ lancet/article/PIIS0140-6736(16)31389-7/fulltext (accessed September 2020).

Ezeh, Alex, Oyebode, Oyinlola, Satterthwaite, David, Chen, Yen-Fu, Ndugwa, Robert, Sartori, Jo, et al. "The history, geography, and sociology of slums and the health problems of people who live in slums." October 16, 2016. https://www.thelancet.com/journals/lancet/ article/PIIS0140-6736(16)31650-6/fulltext (accessed September 2020).

Lu, Chunling, Black, Maureen M., and Richter, Linda M. "Risk of poor development in young children in low-income and middle-income countries: an estimation and analysis at the global, regional, and country level." October 4, 2016. https://www.thelancet.com/ journals/langlo/article/PIIS2214-109X(16)30266-2/ fulltext (accessed September 2020).

Mwase, I., Mutoro, A., Owino, V., Garcia, A. L., and Wright, C. M. "Poor infant feeding practices and high prevalence of malnutrition in urban slum child care centres in Nairobi: A pilot study." February 2016. https://www.ncbi.nlm.nih.gov/pubmed/26507408 (accessed September 2020).

Olack, B., Burke, H., Cosmas, L., Banrah, S., Dooling, K., Feikin, D. R., Talley, L. E., and Breiman, R. F. "Nutritional status of under-five children living in an informal urban settlement in Nairobi, Kenya." August 29, 2011. https://www.ncbi.nlm.nih.gov/ pubmed/21957674 (accessed September 2020). 
Richter, Linda, Daelmans, Bernadette, Lombardi, Joan, Heymann, Jody, Lopez Boo, Florencia, and Behrman, Jere. "Investing in the foundation of sustainable development: pathways to scale up for early childhood development." October 4, 2016. https:// www.thelancet.com/journals/lancet/article/PIIS01406736(16)31698-1/fulltext (accessed September 2020).

\section{Acknowledgements}

We are grateful to the funders that have made this work possible, including our lead funder the Peter T. Paul Innovation Fund at the Peter T. Paul College of Business \& Economics at the University of New Hampshire. We also acknowledge the support of the International Franchise Association's Social Sector Task Force, which provided volunteer mentor Peter Holt of The Joint Chiropractic who both served as an integral contributor to the Social Sector Franchise Accelerator and guided Kidogo throughout the course of this case study. We also thank Kidogo's Co-Founder and Chief Exploration Officer Sabrina Habib for providing extensive access to the company information upon which this case study was based.

\section{About the Authors}

Jill Howard is a 2019 graduate of the University of New Hampshire. Jill received a B.S. in Business Administration with a concentration in Social Innovation and Enterprise and a minor in Women's Studies. She worked for the Center for Social Innovation and Enterprise at UNH from January 2016 through 2019. She now works as a Sustainable Retail Reporting Analyst at Ahold Delhaize.

Fiona Wilson is the Director of the Sustainability Institute at the University of New Hampshire. Previously, from 2016-2020, she was the executive director of the Center for Social Innovation and Enterprise; she is also an affiliate clinical associate professor of Social Innovation, Social Entrepreneurship, and Sustainability, Department of Management at The Peter T. Paul College of Business and Economics at the University of New Hampshire (fiona.wilson@unh.edu).

E. Hachemi Aliouche is the director of the Rosenberg International Franchise Center and Associate Professor at The Peter T. Paul College of Business and Economics at the University of New Hampshire (hachemi.aliouche@unh.edu).

\section{NI University of New Hampshire Carsey School of Public Policy}

The Carsey School of Public Policy at the University of New Hampshire is nationally recognized for its research, policy education, and civic engagement. The school takes on pressing public issues with unbiased, accessible, and rigorous research; builds the policy and political problem-solving skills of its students; and brings people together for thoughtful dialogue and practical problem-solving.

Huddleston Hall • 73 Main Street • Durham, NH 03824 • (603) 862-2821 • TTY UsERs: DIAL 7-1-1 OR 1-800-735-2964 (RELAY N.H.) 